\title{
Evaluation of psychometric properties of the Persian version of the short form of Cognitive Emotion Regulation Questionnaire (CERQ-18)
}

\author{
Hamid Mohsenabadi ${ }^{1}$, Ali Fathi-Ashtiani ${ }^{1 *}$ \\ 1. Behavioral Sciences Research Center, Baqiyatallah University of Medical Sciences, Tehran, Iran
}

Received: 29 January 2021

Accepted for publication: 20 April 2021

[EPub a head of print- 24 April 2021]

Payesh: 2021; 20 (2):167-178

\begin{abstract}
Objective: Cognitive emotion regulation represents an essential role in managing stressful events in people's lives. Some strategies are adaptive, while others are maladaptive and associated with various forms of psychopathology. This study aimed to investigate the factor structure and psychometric properties of the Persian version of the short form of the Cognitive Emotion Regulation Questionnaire (CERQ-18) among Staff of a Military University.

Methods: This was a psychometric research. The statistical population of this study was one of the military units in Tehran. Based on the inclusion and exclusion criteria, 310 people were selected by convenience sampling method. The instruments used included the Cognitive Emotion Regulation Questionnaire (CERQ-18), the Depression, Anxiety and Stress Scale (DASS-42) and the General Job Satisfaction Scale (GJSS). Structural validity was examined by performing confirmatory factor analysis. Cronbach's alpha coefficients and test-retest were used to evaluate the reliability. The data were analyzed using SPSS-25 and AMOS-22.

Results: Confirmatory factor analysis results indicated a two-factor model of this questionnaire (RMSEA=0.03; SRMR=0.02; $\mathrm{CFI}=0.98$; GFI=0.94). The correlation scores of adaptive coping strategies with depression $(-0.48)$, anxiety $(-0.44)$, stress $(-$ $0.46)$ and job satisfaction $(0.36)$ were significant $(\mathrm{p}<0.01)$ Also, the correlation of the scores of maladaptive coping strategies with depression (0.55), anxiety (0.42), stress $(0.40)$ and job satisfaction $(-0.30)$ was significant $(p<0.01)$. The reliability coefficients of Cronbach's alpha and test-retest at 4-weeks intervals for adaptive coping strategies were $0.95,0.88$ and for maladaptive coping strategies was 0.88 and 0.77 , respectively, indicating satisfactory results.

Conclusion: According to the findings of the present study, the short form of the Iranian version of Cognitive Emotion Regulation Questionnaire (CERQ-18) is a suitable tool with good psychometric properties to measure cognitive coping strategies.
\end{abstract}

Key Words: Cognitive emotion regulation, psychometric properties, short form of Cognitive Emotion Regulation Questionnaire

\footnotetext{
${ }^{*}$ Corresponding author: Baqiyatallah University of Medical Sciences, Tehran, Iran

E-mail: afa1337@gmail.com
} 


\title{
بررسى ويزٔى هاى روانسنجى نسخه فارسى فرم كوتاه يرسشنامه تنظيم هيجان شناختى (CERQ -18)
}

\author{
حميد محسن آبادى ! على فتحى آشتيانى 1* \\ ا. مركز تحقيقات علوم رفتارى، دانشَاه علوم يزشكى بقيه الهه (عج)، تهران، ايران

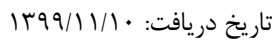

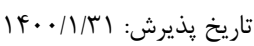

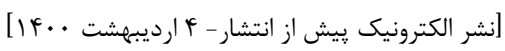

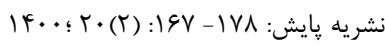

جكيده

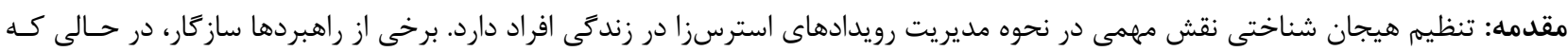

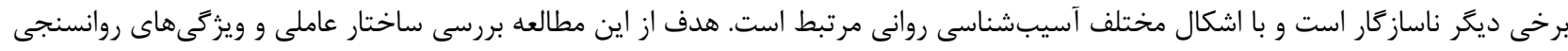

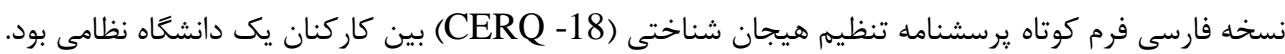

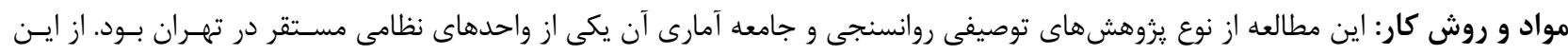

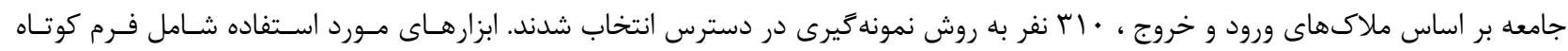

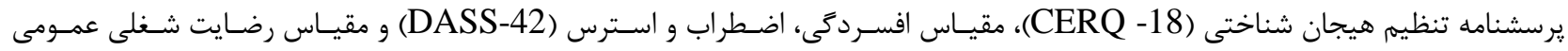

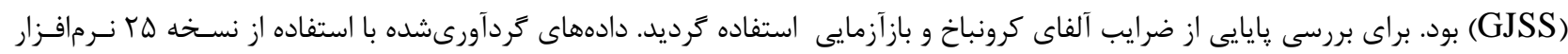

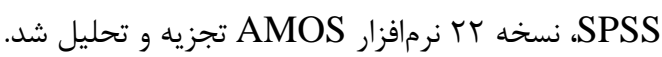

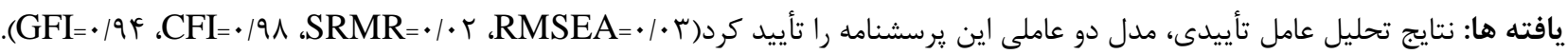

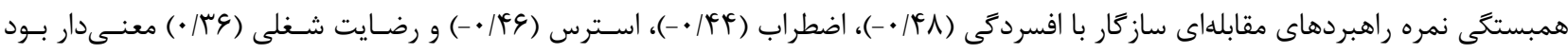

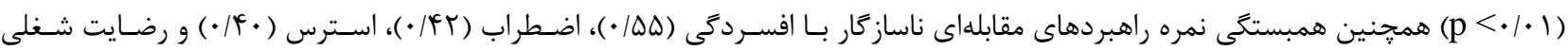

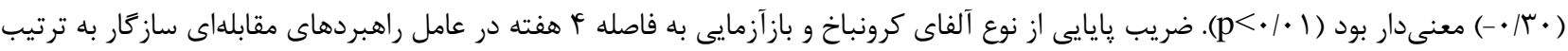

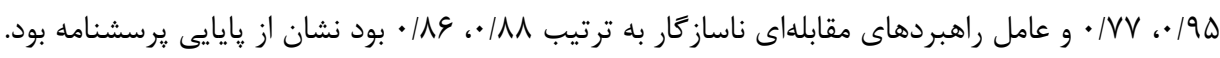

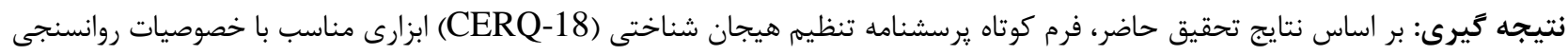

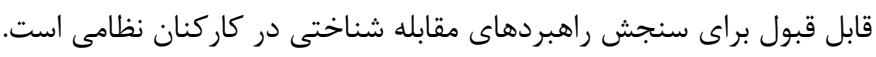

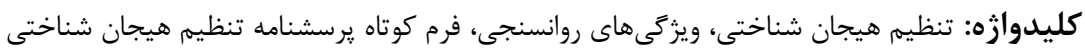




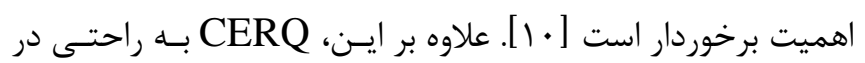

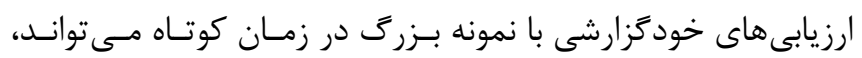

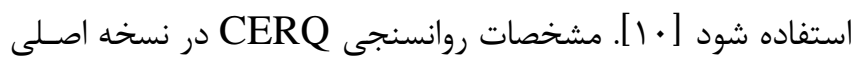

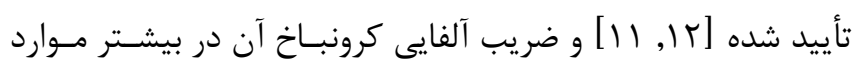

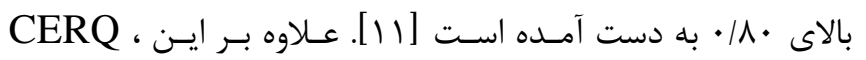

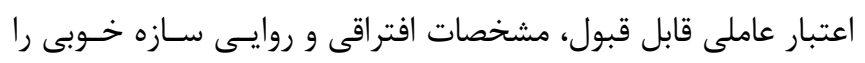

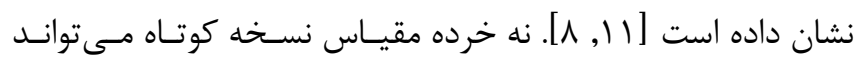

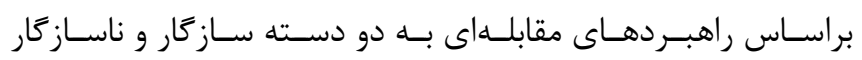

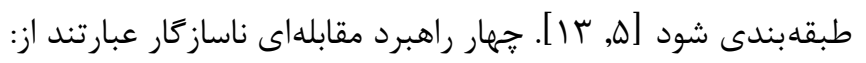

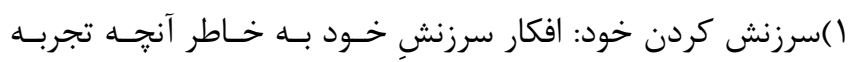

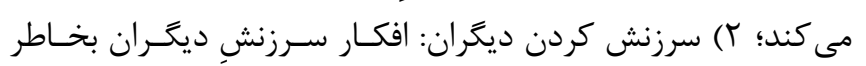

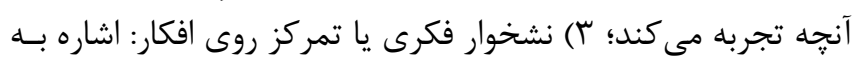

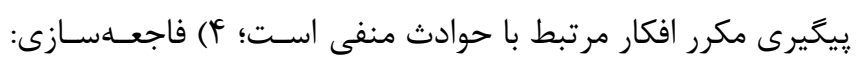

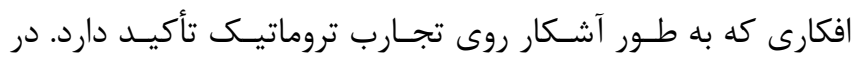

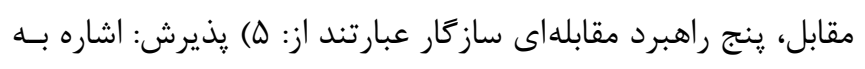

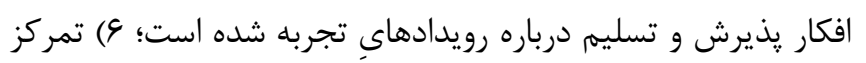

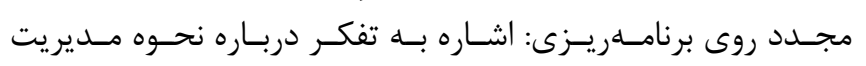

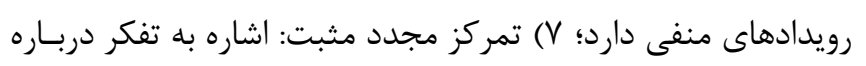

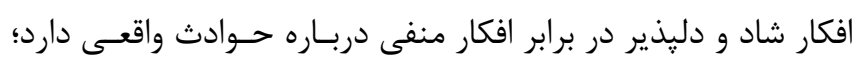

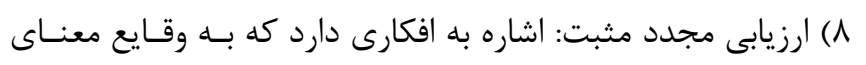

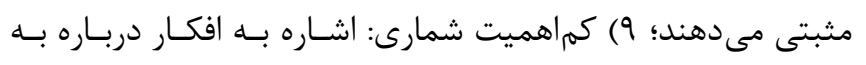

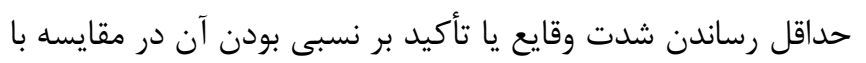
حوادث ديخر دارد [ه]]. اين راهبردهاى تنظيم هيجان شناختى همه با وجود يا عدم آسـيب إنا.

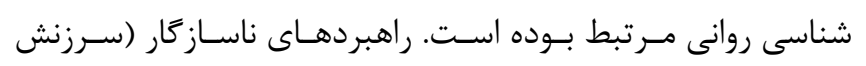

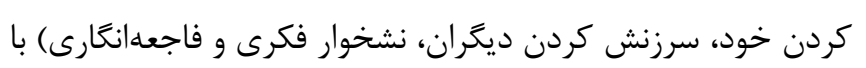

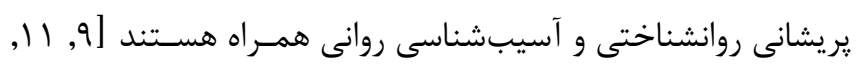

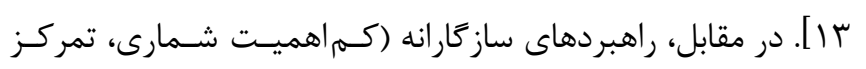

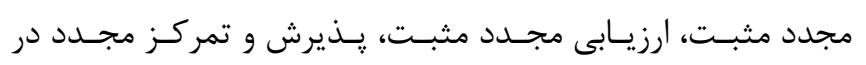

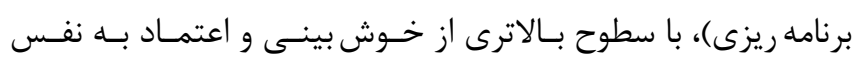

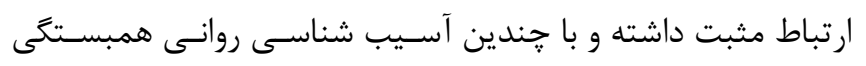

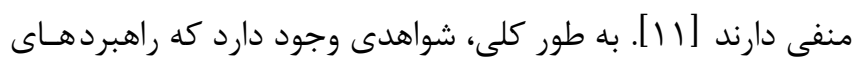

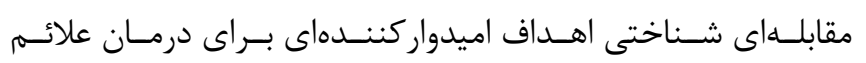

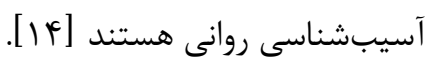

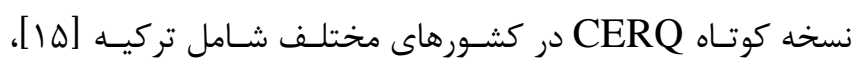

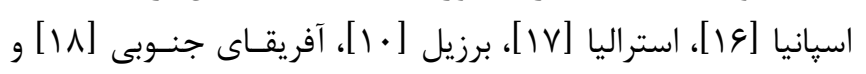

به طور كلى مشخص شده است كه مواجهه با رويـدادهاى منفـى در

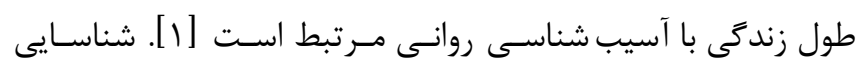

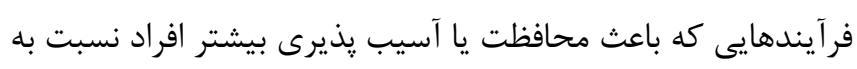

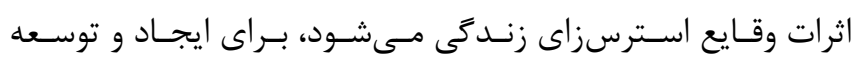

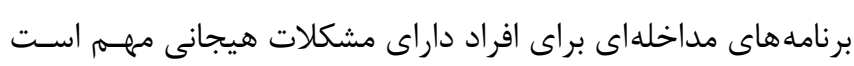

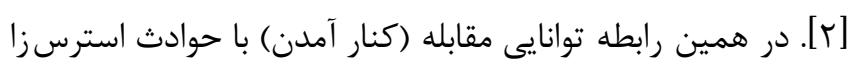

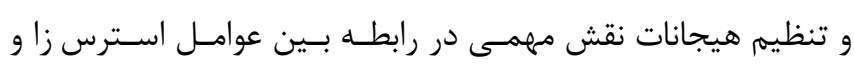

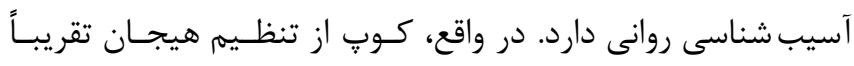

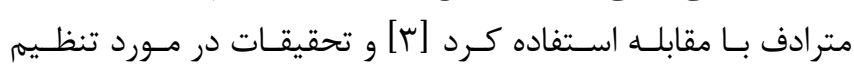

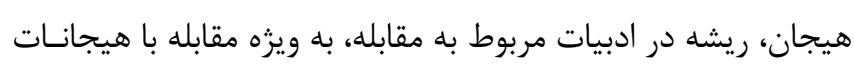

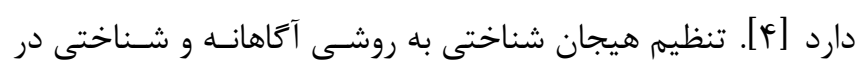

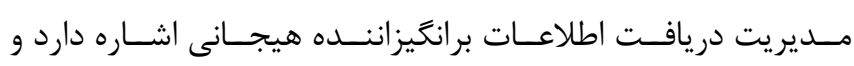
منعكس كننده بخش شناختى مقابله است [هـا

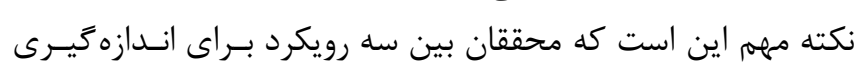

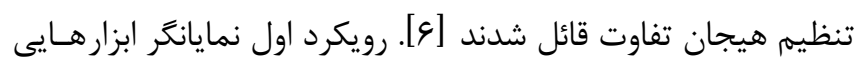

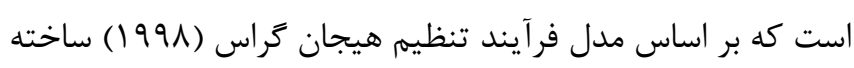

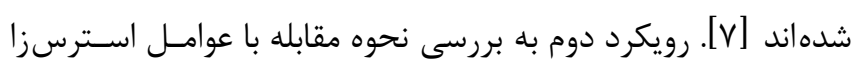

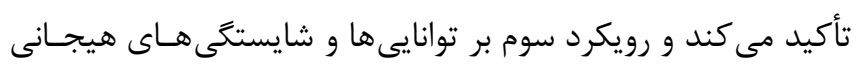

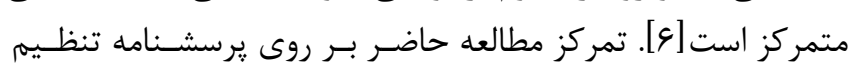

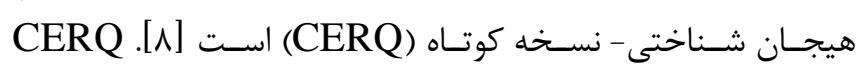

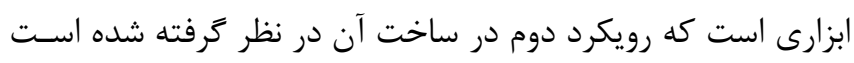

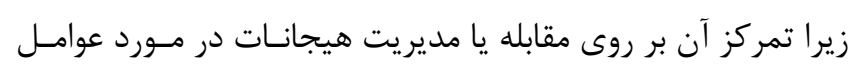

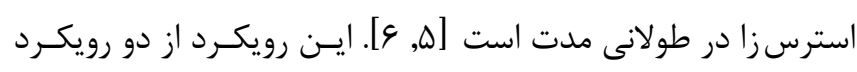

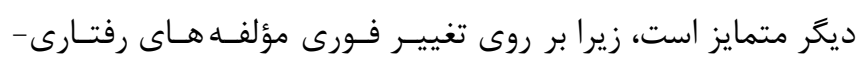

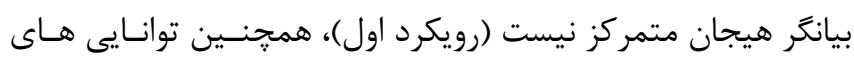

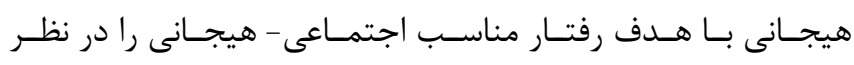

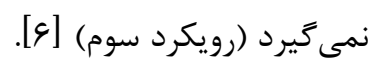

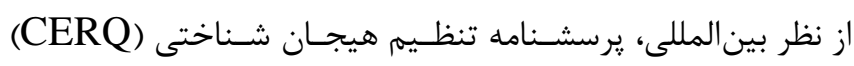

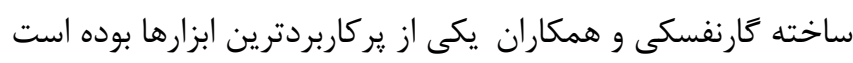

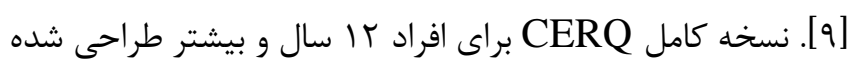

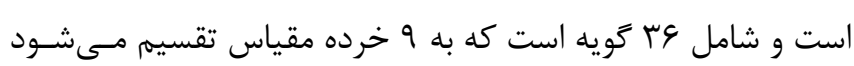

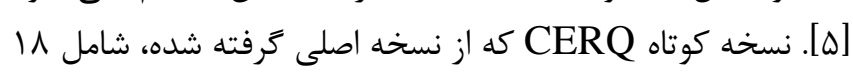

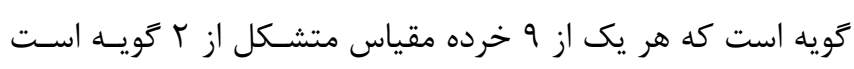

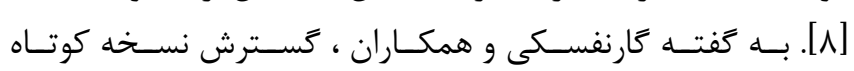

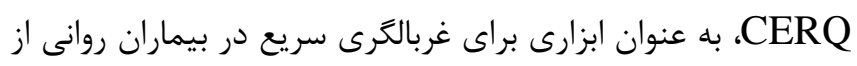


هيجان شناختى توسط كارنفسكى و همكاران در سال 9. •. ساخته شد كه يك يرسشنامه جندبعدى است و جهت شناسايى راسئ راهبردهاى

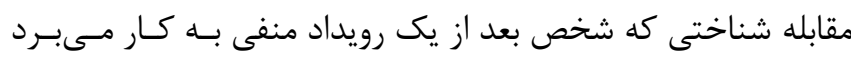

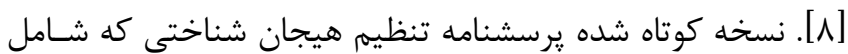

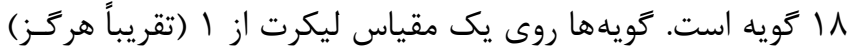

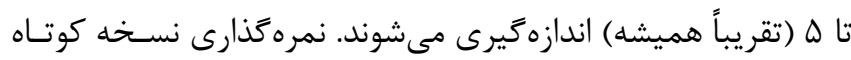

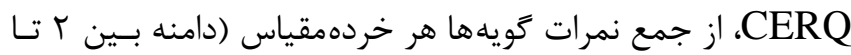

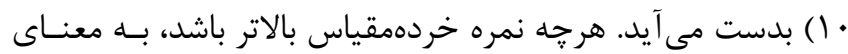

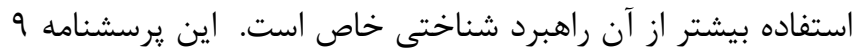
راهبرد مقابلهاى ارزيابى مجدد مثبت، خود سرزنشى، تمركـز مجــد إدي

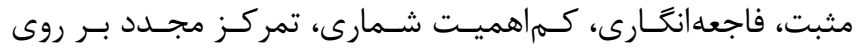

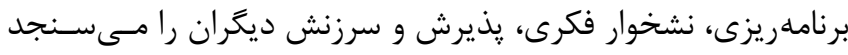

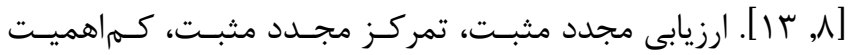

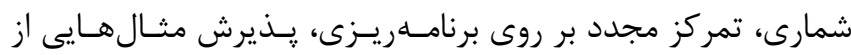

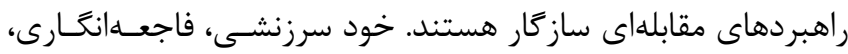

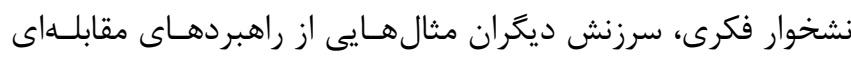

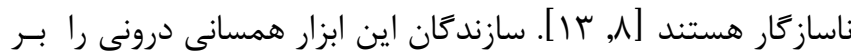

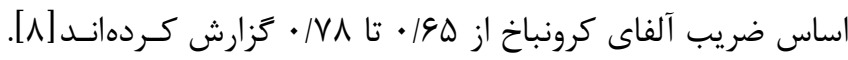

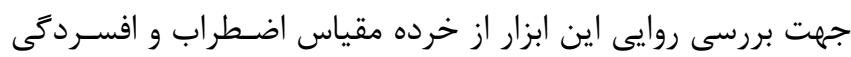

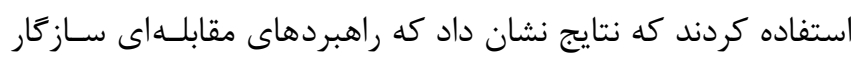

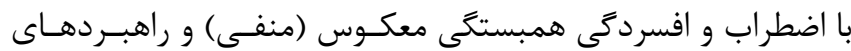

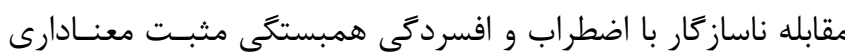

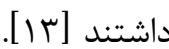

Depression, Anxiety ( مقياس افسردگى، اضطراب و اسـترس and Stress Scale

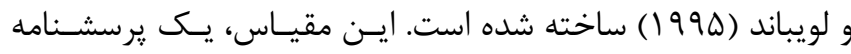
خود كزارشى است كه آزمودنى بايد شدت (فراوانى) علامـت مطـرح شده در هر عبارت را كه در طول هفتهى كذشته تجربه كراس كرده اسـت

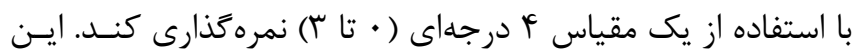

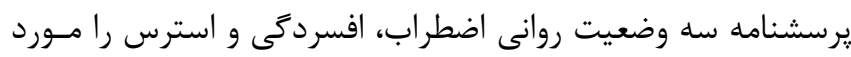

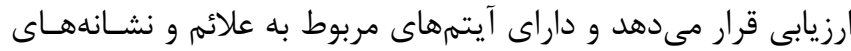

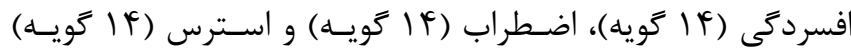

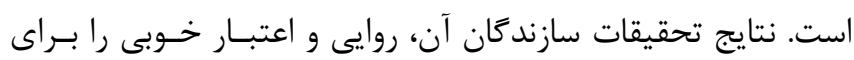

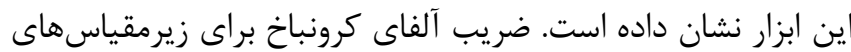

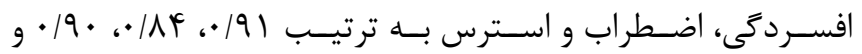

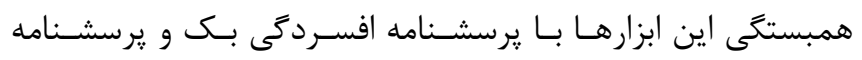

ايران[ [9] ] از لحاظ روانسنجى مورد بر رسى و تأييد شــده اسـت. بـا توجه به موارد كفته شده، حداقل به جهار دليل، هنجاريـابى نسـخه

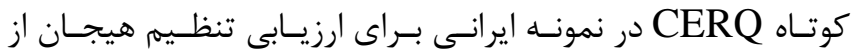

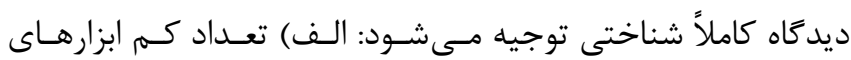

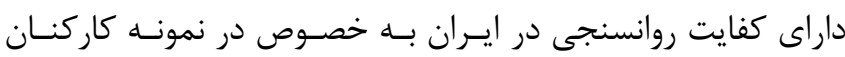

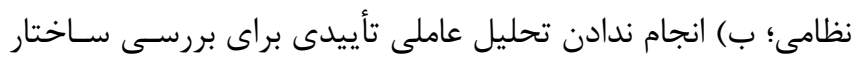

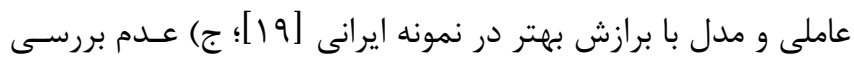

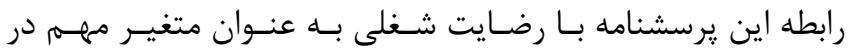

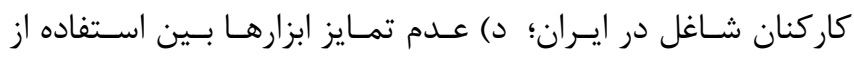
راهبردهاى شناختى و رفتارى براى تنظيهم هيجـانهـا

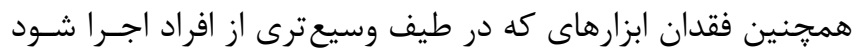

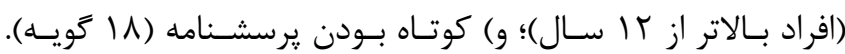

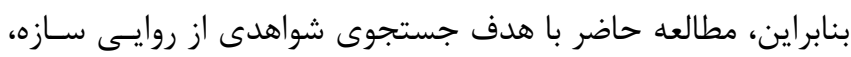
همسانى درونى و شاخصهاى روانسنجى نسخه فارسى يرسشـانهامه

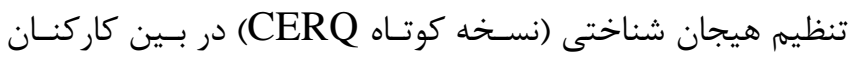
يك دانشعاه نظامى است.

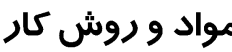

طرح يزوهش حاضر توصيفى و از نـوع مطالعـات روانسـنجى اسـت.

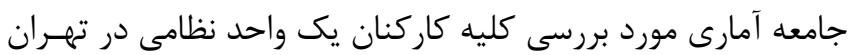

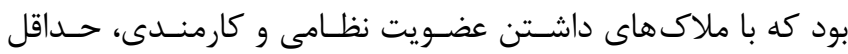
تحصيلات دييلم، شاغل در مركز نظامى، حـداقل يـك سـال سـابقه

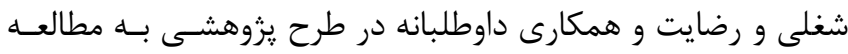

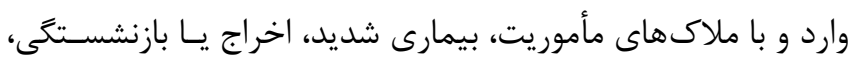
تكميل ناقص يرسشنامه، عدم تمايل براى ادامه همكـارى از مطالعـهـ

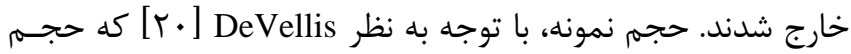

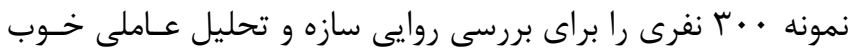

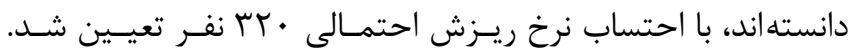

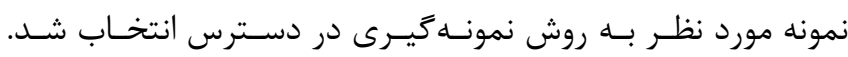

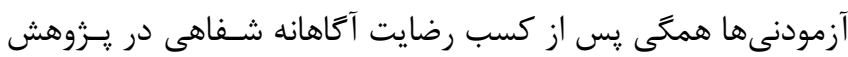

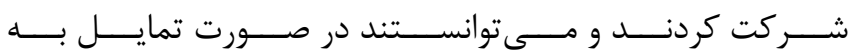

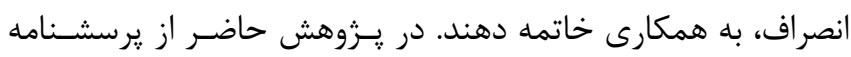

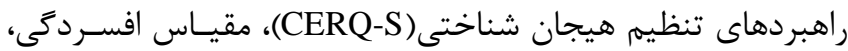

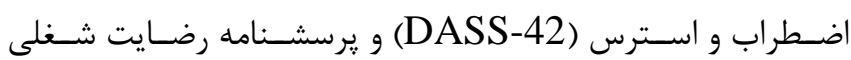
(GJSS)

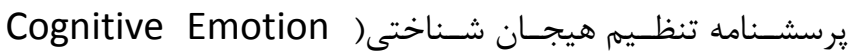
Regulation Questionnaire-Short 
يكديكر هماهنگ شد. فرم ترجمه شده به همراه يك نسـخه از ابـزار

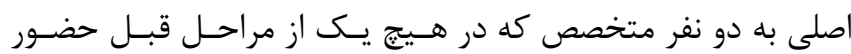

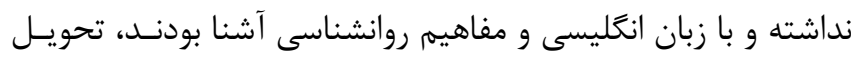
داده شد و از آنها خواسته شد تا مطابقت فرم ترجمه شــده و ابـزار

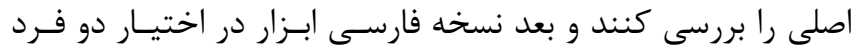

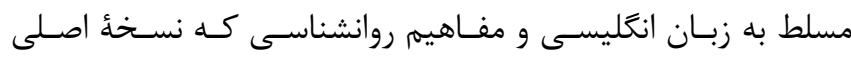

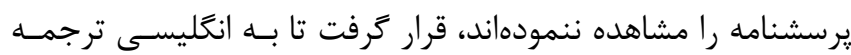

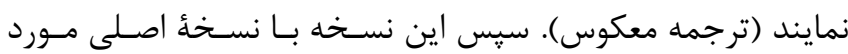

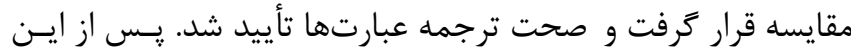

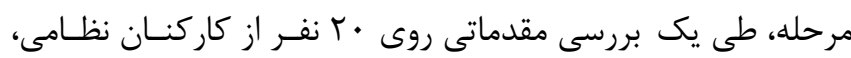

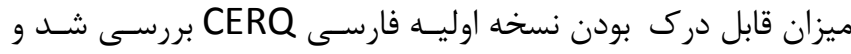
يس از رفع نواقص، يرسشنامه براى اجرا در نمونه اصلى آماده شد.

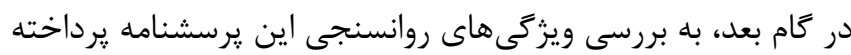

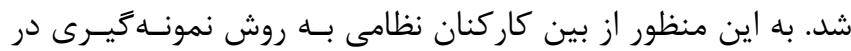

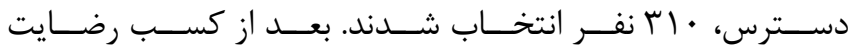

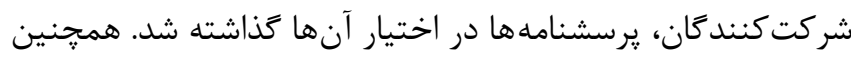

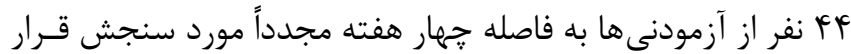

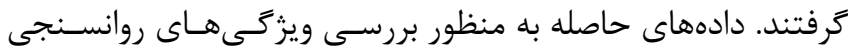

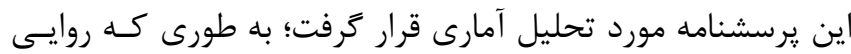

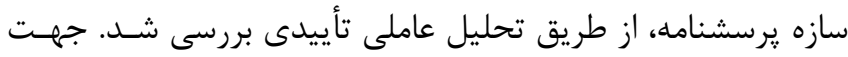

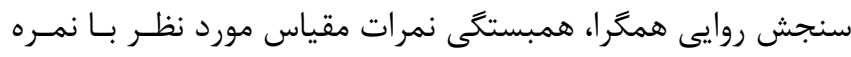

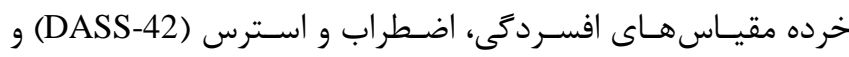

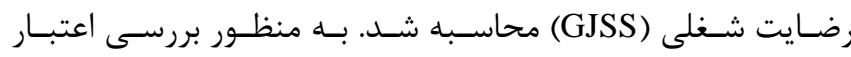

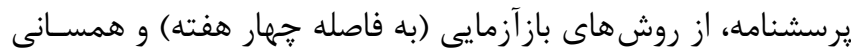
درونى (آلفاى كرونباخ) استفاده شد.

\section{يافتهها}

توزيع فراوانى و درصد اطلاعات جمعيت شناختى شـركت كنـــدكان در مطالعه در جدول ا نمايش داده شده است. بـر اسـاس اطلاعـات فردات

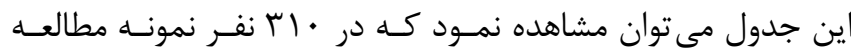

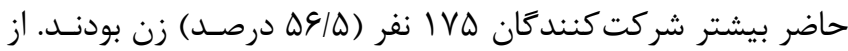

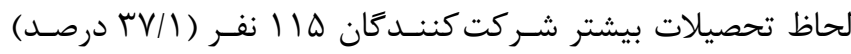
داراى مدرك كارشناسى ارشد بودند و از لحاظ وضعيت تأهل بيشتر

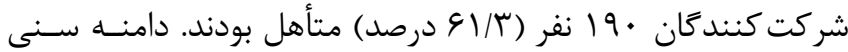

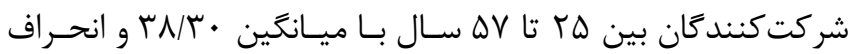

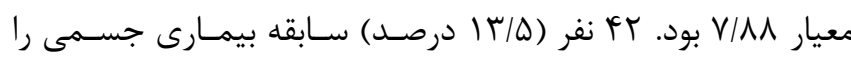

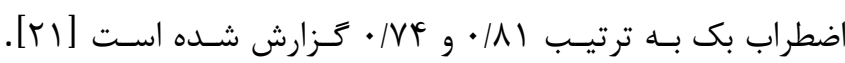

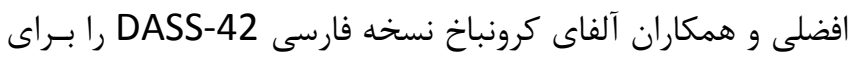

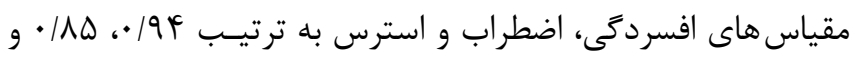

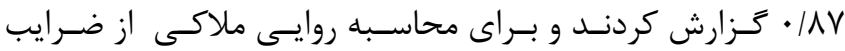

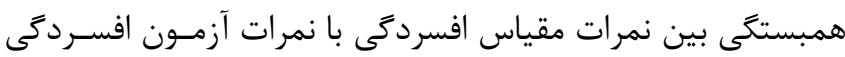

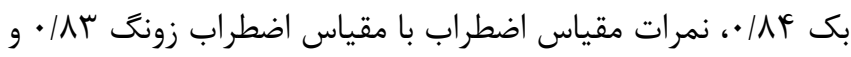

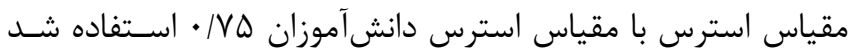

[rr] $(P<\cdot / \cdot 1)$

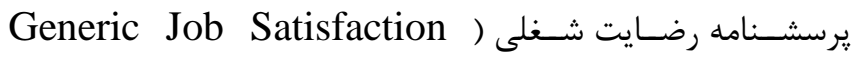

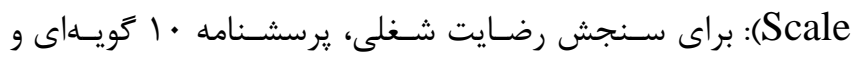

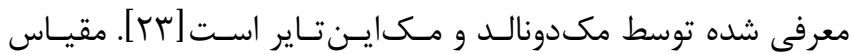

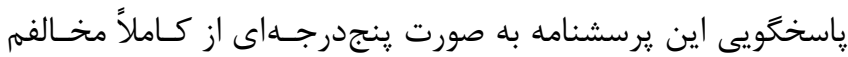

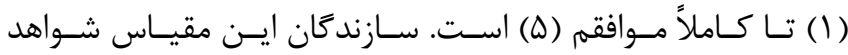
كسترداى از روايى سازه، همكرا و تشخيصى ايـن يرسشـنامه ارائهـ

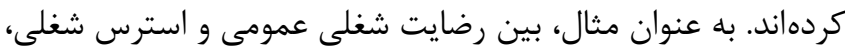

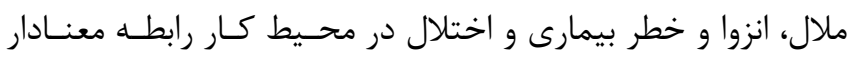

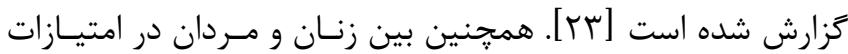
اين مقياس تفاوت معنادار به دست نيامده و تحليل عامل اكتشـافى،

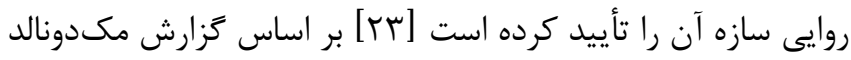

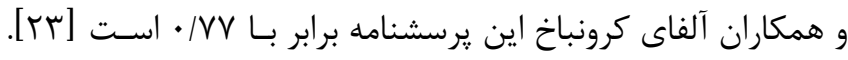

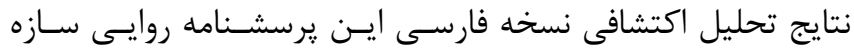

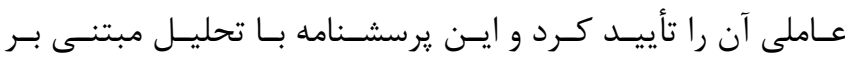

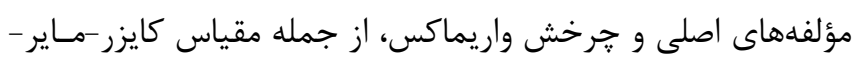

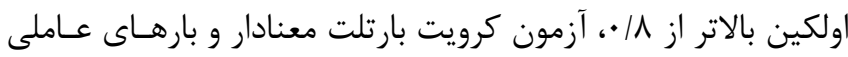

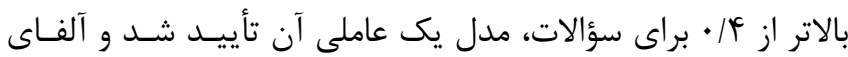

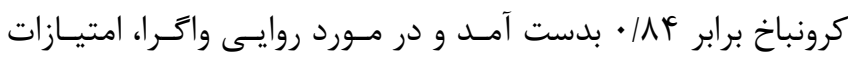
حاصل از اين يرسشنامه با استرس شغلى و فرسودى هيج هيجانى رابطه

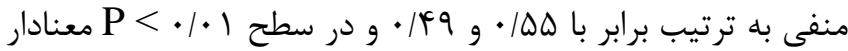

نشان داد [ry]

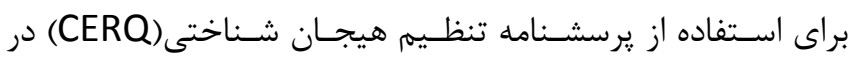

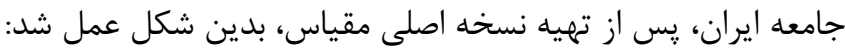

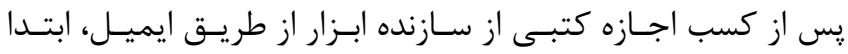

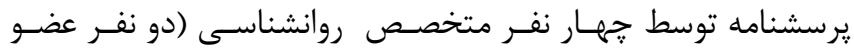

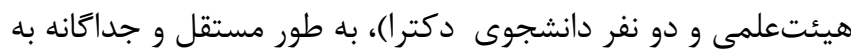
زبان فارسى ترجمه شد و سيس ترجمه هاى انجام شده در يك كروهائ

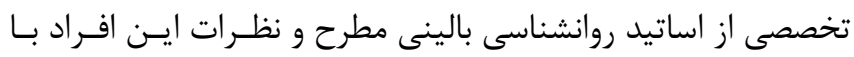




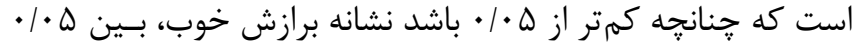

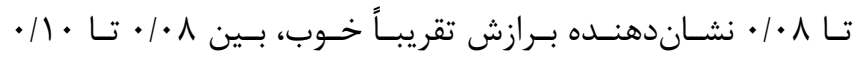

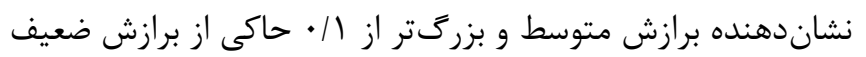

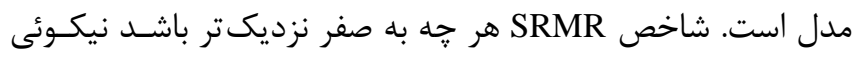

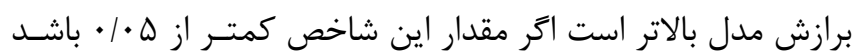

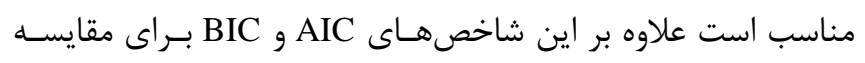

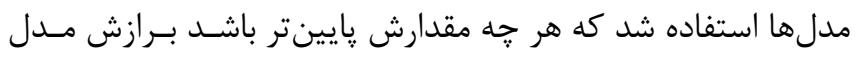

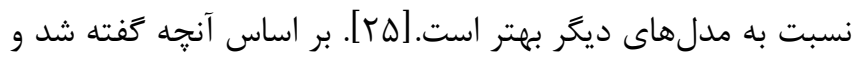

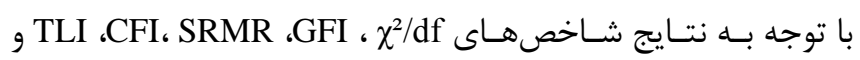

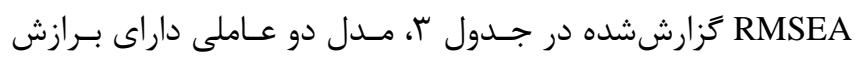

مناسبى است درنتيجه، اين مدل تأييد شد (شكل إن ().

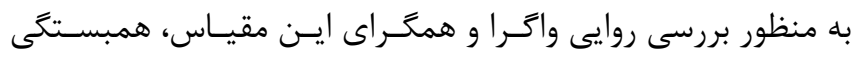

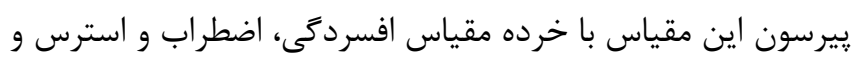

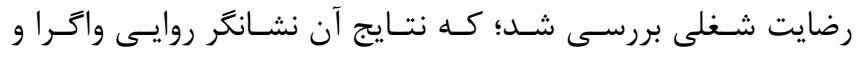
همكراى اين مقياس بود. نتايج در جدول ثأ ارائه شده است.

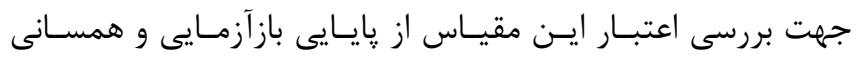

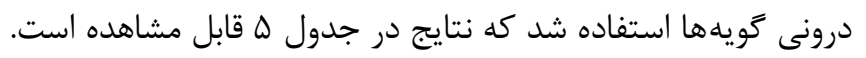

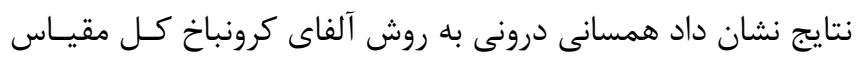

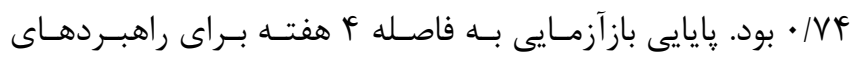

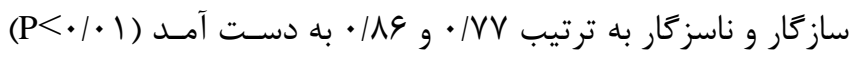
كه نشان مىدهد ابزار اعتبار خوبى دارد.
داشتند كه با نفر اختلال گوارشى، 9 نفر اختلال قلبى و عروقى،

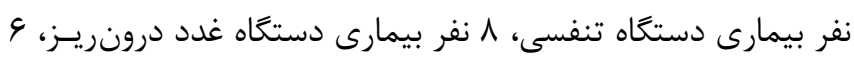

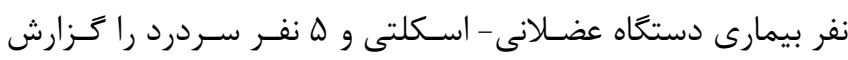

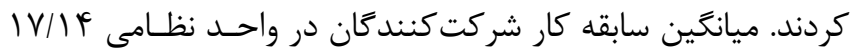

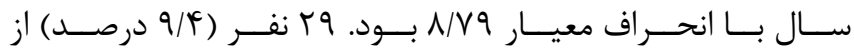

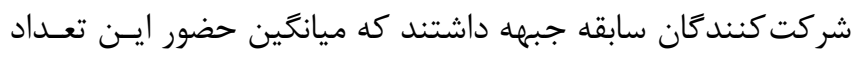

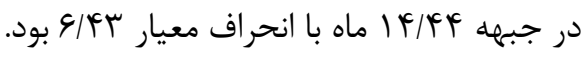
بامنظور اطمينان از صحت سـاختار عـاملى، از روش تحليـل عامـل

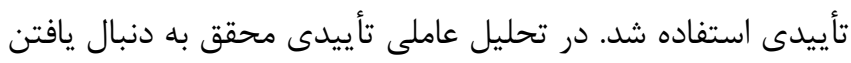

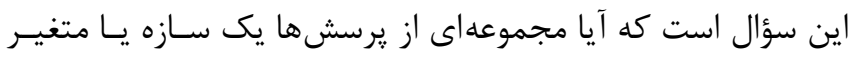

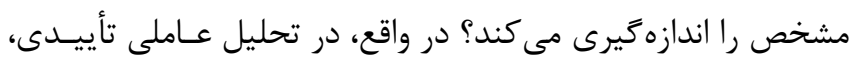

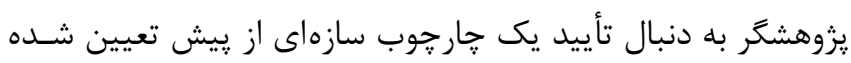

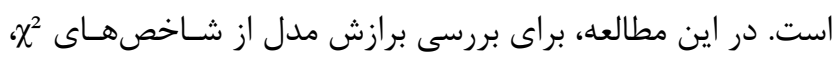

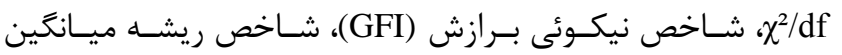

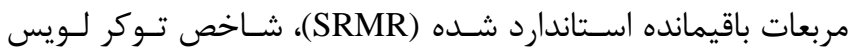

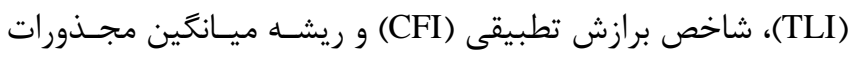

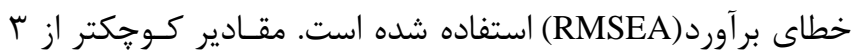

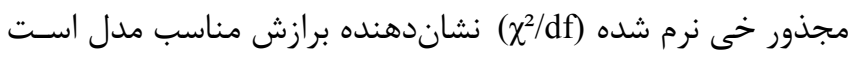

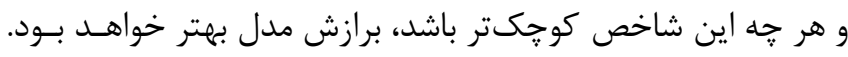

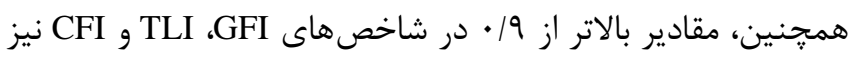

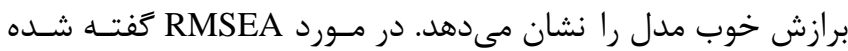

جدول ا: اطلاعات جمعيت شناختى شركتكنندكان در مطالعه بر اساس توزيع فراوانى و درصد

\begin{tabular}{|c|c|c|c|}
\hline مرصد & تعداد & & \\
\hline 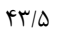 & irs & 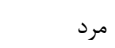 & جنسيت \\
\hline$\Delta \varepsilon / \Delta$ & $I V \Delta$ & 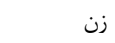 & \\
\hline $1 \pi / r$ & +1 & $r \cdot-r$. & سن \\
\hline$\Delta N / \mathcal{F}$ & $|1|$ & $\mu_{1}-\boldsymbol{r}$. & \\
\hline $1 \pi / 9$ & er & $f \mid-\Delta$. & \\
\hline $1 F / 0$ & $f \Delta$ & $\Delta 1-8$. & \\
\hline$\Delta / \Delta$ & IV & دييلم & مقطع تحصيلات \\
\hline$V / 1$ & rt & فوقدييلم & \\
\hline$r) / 9$ & $9 \Lambda$ & ل ليسانس & \\
\hline$r v / l$ & 110 & فوقليسانس & \\
\hline TN/F & M & دكترى & \\
\hline $41 / 4$ & 19. & متأهل & وضعيت تأهل \\
\hline 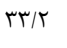 & $1 \cdot r$ & مجرد - & \\
\hline$\Delta / \Delta$ & IV & مطلقه & \\
\hline $1 \pi / \Delta$ & fr & 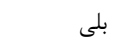 & سابقه بيمارى جسمى \\
\hline$\Lambda 9 / 0$ & reN & خير & \\
\hline
\end{tabular}


If.. سال بيستم، شماره دوم، فروردين - ارديبهشت

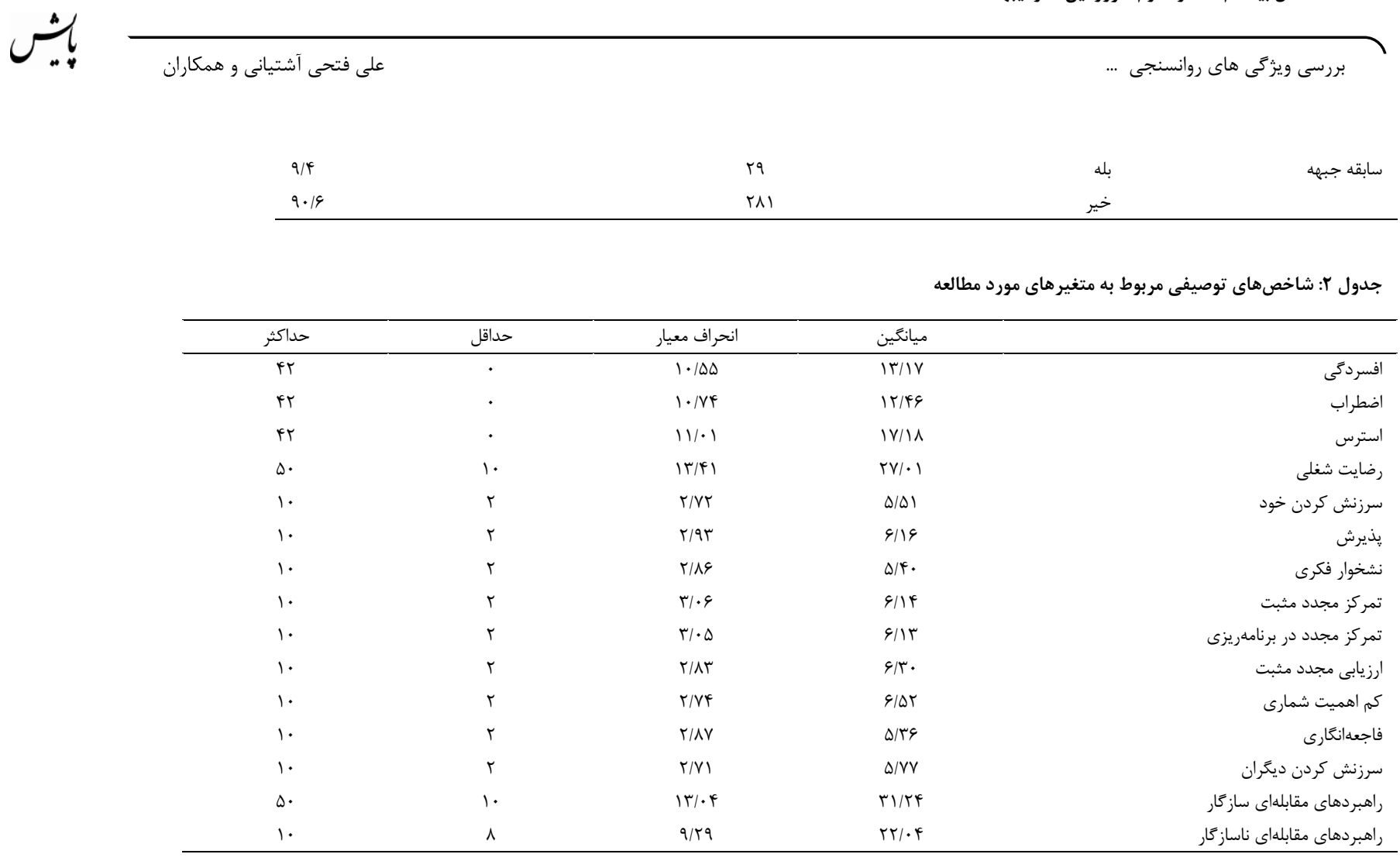

جدول r: نتايج تحليل عاملى تأييدى CERQ-S

\begin{tabular}{|c|c|c|c|c|c|c|c|c|c|c|}
\hline $\begin{array}{l}\text { RMSEA } \\
(90 \% \mathrm{CI})\end{array}$ & BIC & AIC & SRMR & CFI & TLI & GFI & $\chi^{2 / \mathrm{df}}$ & df & $\chi^{2}$ & شاخصل شاىبرازش \\
\hline $\begin{array}{c}\cdot / 1 \cdot \\
(\cdot / 11-\cdot / \cdot 9)\end{array}$ & $119 / 99$ & GDI/ND & . /Irs & $\cdot 119$ & $\cdot 119$ & $\cdot 1 \mathrm{~A}$ & $f / F \Delta$ & ITS & $\Delta G 1 / \wedge \Delta$ & مدل يك عاملى \\
\hline $\begin{array}{c}\cdot / \cdot r \\
(\cdot / \cdot r-\cdot / \cdot \Delta)\end{array}$ & FFQ/FF & TVT/DG & $\cdot / \cdot r \Lambda$ &.$/ 91$ &.$/ 91$ &.$/ 9 F$ & $1 / f \Delta$ & ITS & $|N| / \Delta \varphi$ & مدل دو عاملى \\
\hline $\begin{array}{c}\cdot / 11 \\
(\cdot / 1 \cdot-\cdot / 1 r)\end{array}$ & & $919 / \pi 9$ & .1111 & $\cdot 119$ & $\cdot \mid \lambda f$ & $\cdot \mid \mathrm{AV}$ & $f / V V$ & 99 & FVT/Rq & مدل نه عاملى \\
\hline
\end{tabular}

$\chi^{2} / d f$ : chi-square/degrees of freedom; GFI: goodness of fit index; TLI: Tucker-Lewis coefficient; CFI: comparative fit index; SRMR: Standardized Root Mean Square Residual; RMSEA: root mean square error of approximation; AIC: Akaike information criterion

جدول f: نتايج همبستكى بين CERQ ، DASS-42 وضايت شغلى (GJSS)

\begin{tabular}{|c|c|c|c|c|}
\hline رضايت شغلى & مقياس استرس & مقياس اضطراب & مقياس افسردگى & \\
\hline$-\cdot / R \Delta$ & . & ( &.$/ 4 \Delta$ & سرزنش كردن خود \\
\hline$\cdot \pi \cdot$ & $-\cdot / f r$ & $-\cdot|f|$ & $-\cdot|f|$ & يذيرش \\
\hline 每 & 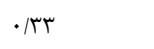 & $\cdot / \mu r$ & .149 & نشخوار فكرى \\
\hline$\cdot / \mu F$ & $-\cdot / f F$ & $-\cdot / 4$ & $-\cdot / 4 F$ & تمركز مجدد مثبت \\
\hline 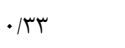 & 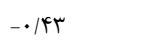 & $-\cdot / r \wedge$ & $-\cdot / f f$ & تمركز مجدد در برنامهريزى \\
\hline Tr & $-\cdot / \Gamma \Lambda$ & $-\cdot / r \Lambda$ &.$- / 4 r$ & ارزيابى مجدد مثبت \\
\hline$\cdot / r \Lambda$ & $-\cdot / r V$ & - - ( & $-\cdot / \mu \wedge$ & كم اهميت شمارى \\
\hline$-\cdot|r|$ & $\cdot / r \cdot$ & $\cdot / \mu F$ & $\cdot|4|$ & فاجعهانگارى \\
\hline$-\cdot / \mu 1$ & $\cdot / 49$ & $\cdot / \pi$ & $\cdot 10$ & سرزنش كردن ديخران \\
\hline 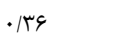 & $-\cdot / 48$ & $-\cdot / 4 F$ & $-\cdot / \uparrow \wedge$ & راهبردهاى مقابلهاى سازگًار \\
\hline$-\cdot / r \cdot$ & $\cdot / 4$ & . $/$ at & $\cdot / \Delta \Delta$ & راهبردهاى مقابلهاى ناساز كار \\
\hline
\end{tabular}


سال بيسته، شماره دوم، فروردين ـارديبهشت ..F

نشريه يزوهشكده علوم بهداشتى جهاددانشكاهى

\begin{tabular}{|c|c|c|c|}
\hline بازآزمايى & آلفاى كرونباخ & آيتمها & \\
\hline$\cdot / N \& * *$ & $\cdot / 1 / 9$ & $1, r$ & سرزنش كردن خود \\
\hline$\cdot / 1 \cdot * *$ & $\cdot / A F$ & $r g$ & يذيرش \\
\hline$\cdot / V \mid * *$ & . IVG & $\Delta, q$ & نشخوار فكرى \\
\hline$\cdot / N r^{* * *}$ & $\cdot / \Lambda \Lambda$ & $v, \wedge$ & تمركز مجدد مثبت \\
\hline$\cdot / \mathrm{V} \cdot * *$ & $\cdot / \Lambda \Lambda$ & $9,1$. & تمركز مجدد در برنامهريزى \\
\hline$\cdot / V r^{* * *}$ & $\cdot \operatorname{lat}$ & 11,14 & ارزيابى مجدد مثبت \\
\hline$\cdot / v \Delta * *$ & $\cdot / 14$ & $|r| f$, & كم اهميت شمارى \\
\hline$\cdot \mid \Lambda \uparrow * *$ & . IV & 10,19 & فاجعهانگًارى \\
\hline$\cdot 11 \cdot * *$ & $\cdot / v \Delta$ & $1 V, \mid 1$ & سرزنش كردن ديكران \\
\hline$\cdot / V V^{* * *}$ & .190 & 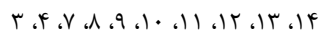 & راهبردهاى مقابلهاى سازگًار \\
\hline$\cdot \mid \Lambda 9 * *$ & $\cdot / 1 \Lambda$ & 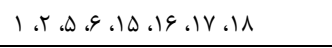 & راهبردهاى مقابلهاى ناساز \\
\hline
\end{tabular}

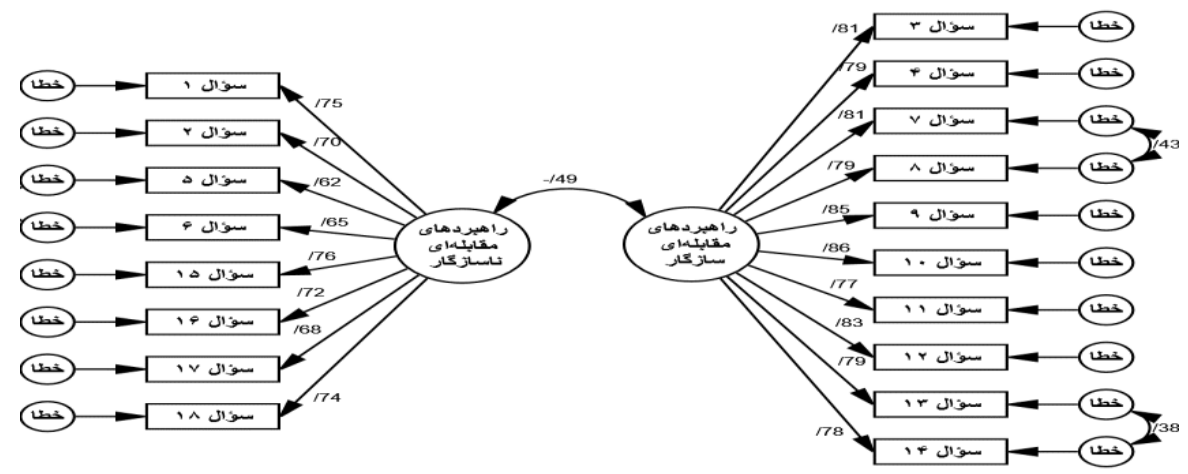

شكل ا: آزمون مدل دو عاملى CERQ-S به همراه ضرايب استاندارد

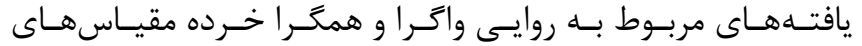
يرسشنامه تنظيم هيجان شناختى با مقياسهاى افسردگى، اضطراب

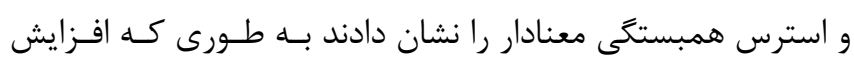

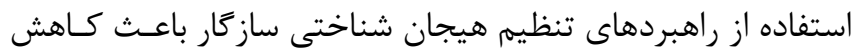

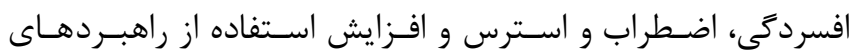

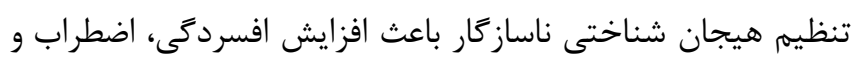

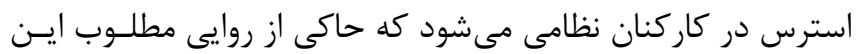

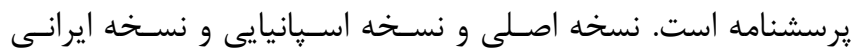

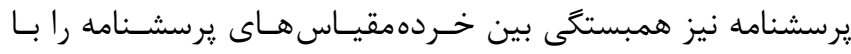
اضطراب و افسردگى نشان دادهاند [9 1, 19 19] به طورى كه مطالعـات 
استرس زا و سلامتى بازى مى كنند [ [ار]. يكى از جنبه هاى حياتى

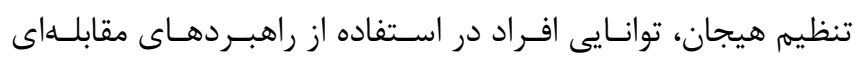

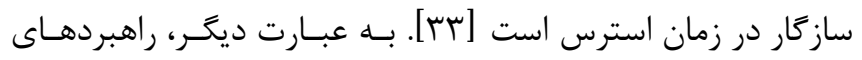

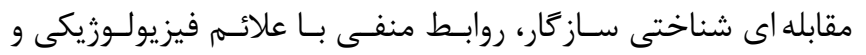

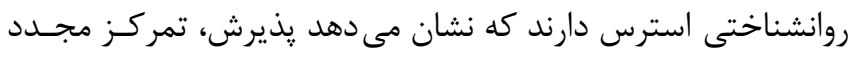

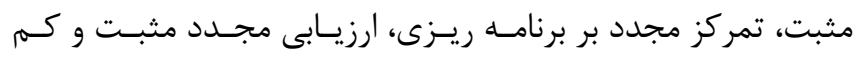

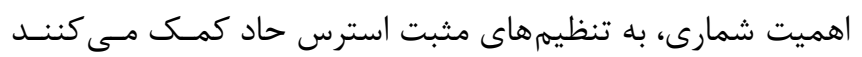

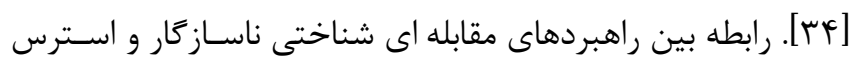

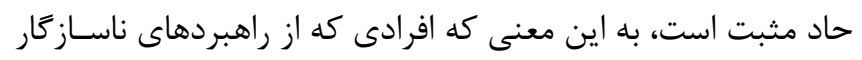

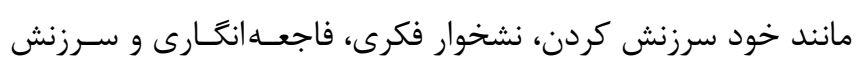

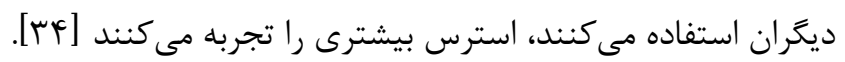

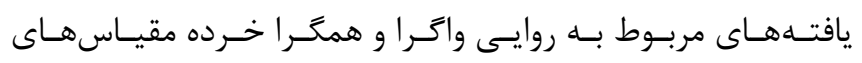

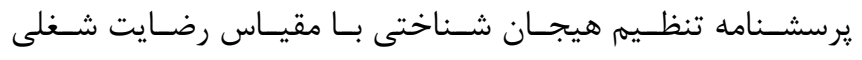

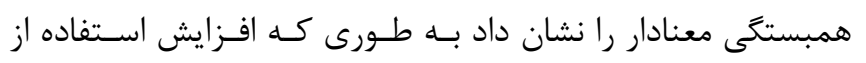

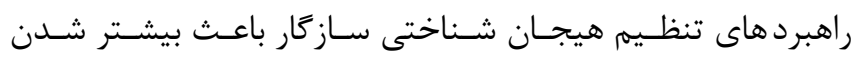

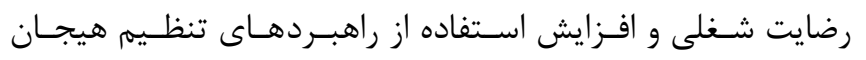

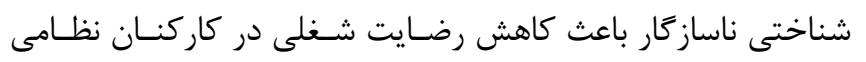

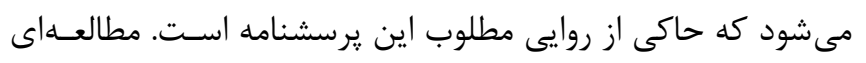

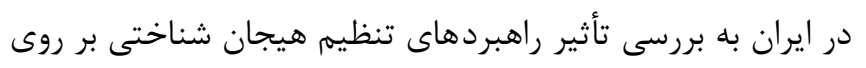

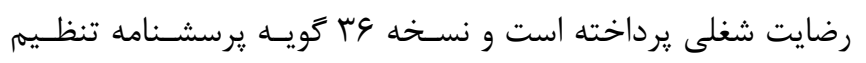

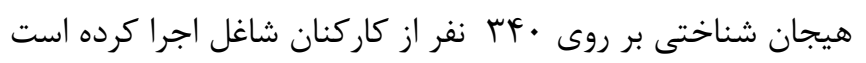

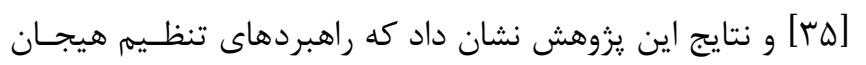

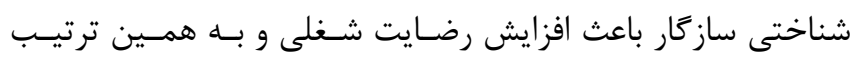

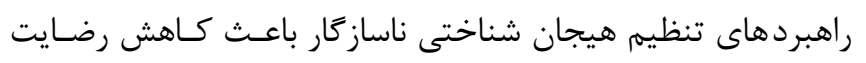

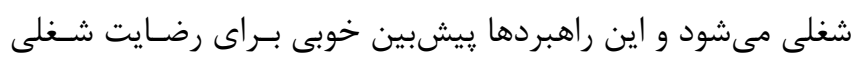

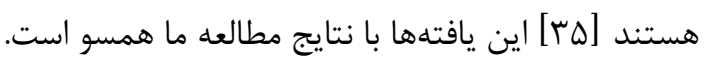

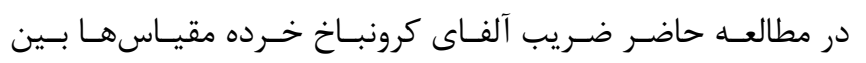

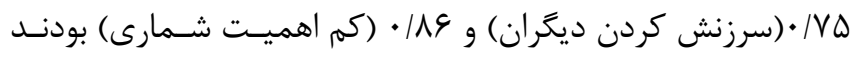

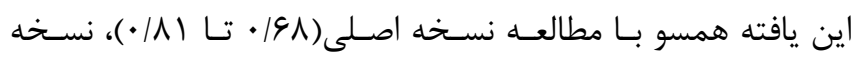

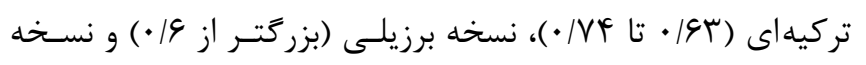

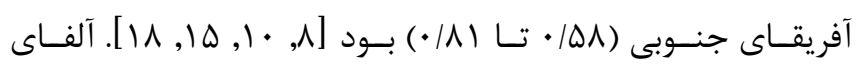

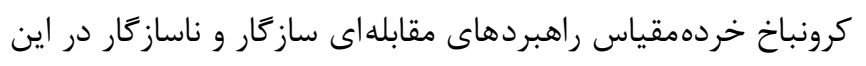

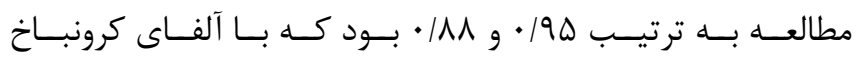

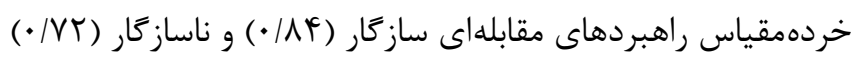

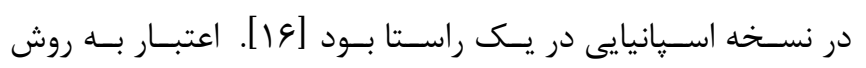

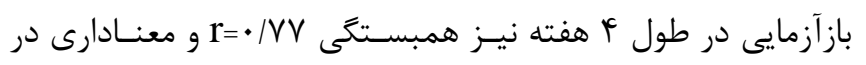

قبلى نيز نشان دادهاند كه ابزار CERQ افسردگى، اضطراب، خشهم

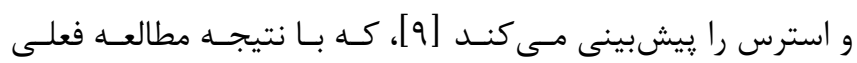
مطابقت دارد.

تصور مى شود كه اجراى انعطاف يـذير راهبـــدهــاى تنظـيم هيجـان

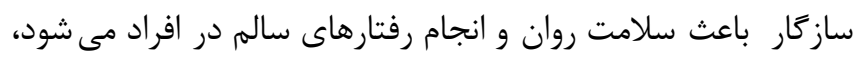

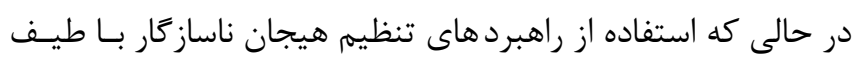

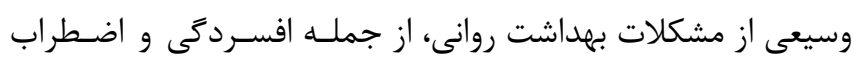

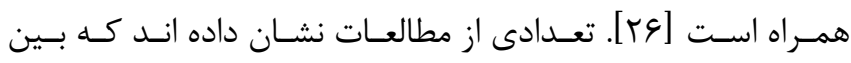

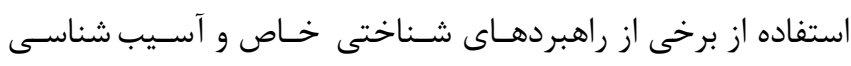

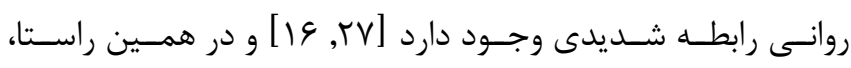

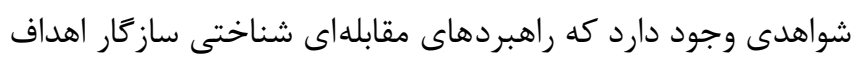

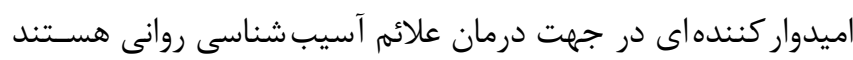

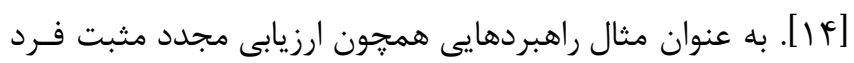

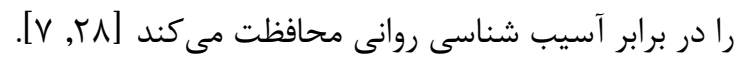

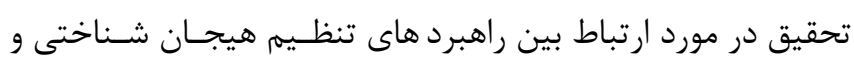

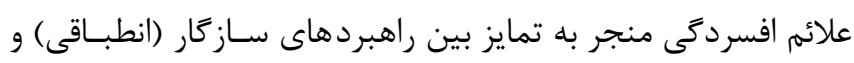

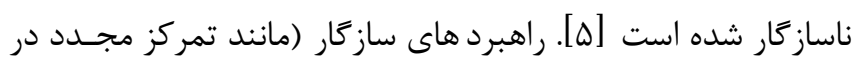

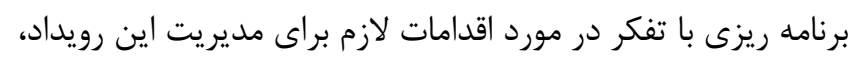

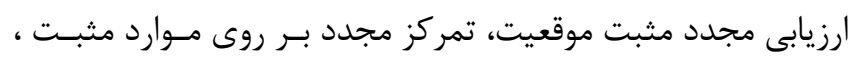

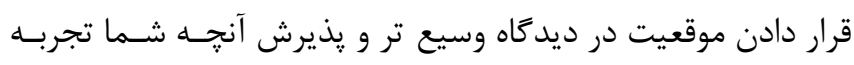

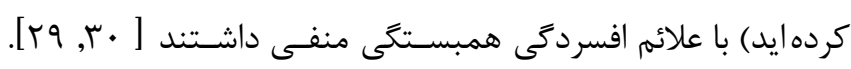

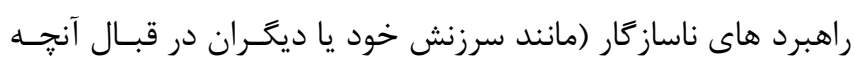

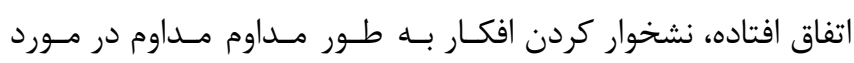

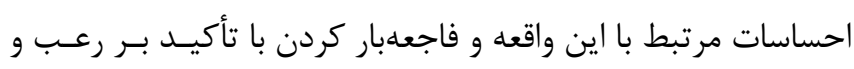

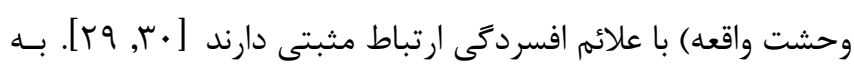

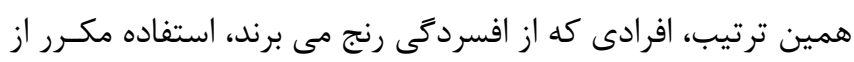

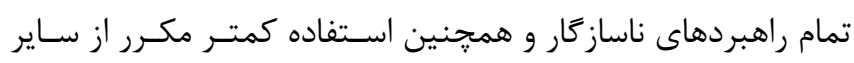

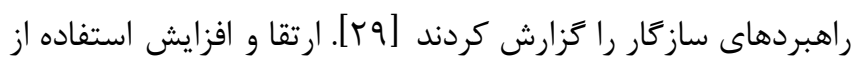

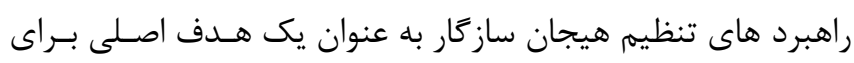

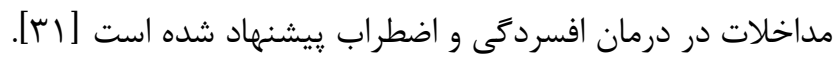

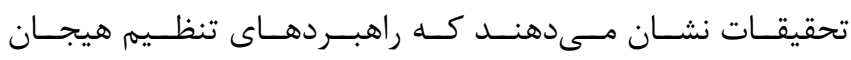

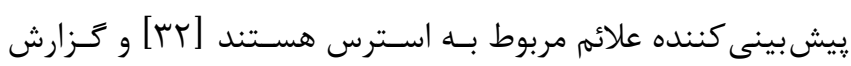

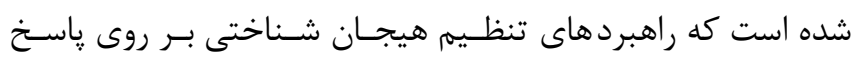

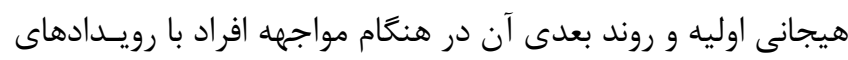

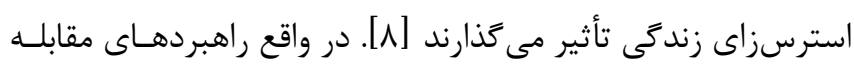

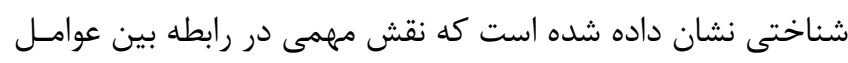


شرايط اضطرارى و بحرانى همجون شرايط كرونـايى) يـا بــه عنــوان ابزارى بالينى براى غربالكرى يا ارزيابى سريع مورد استفاده قرار دارئ دادئ

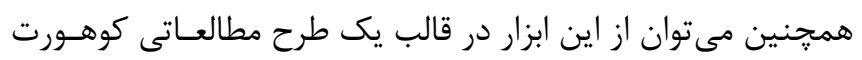

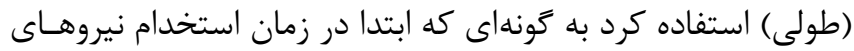

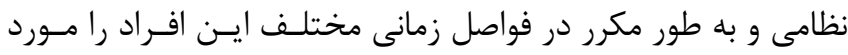

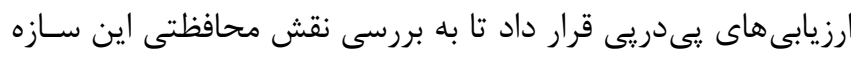

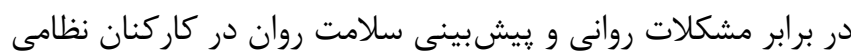

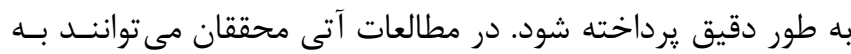

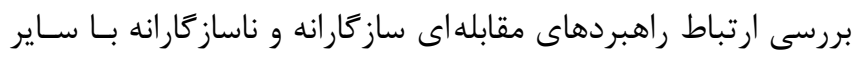

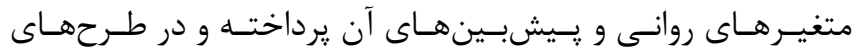

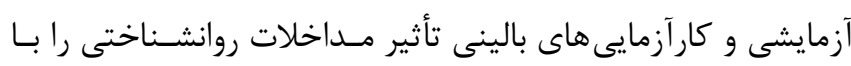

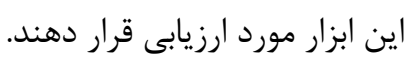

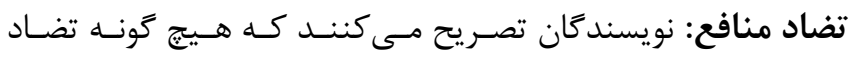
منافعى در مطالعه حاضر وجود ندارد.

\section{سمم نويسند}

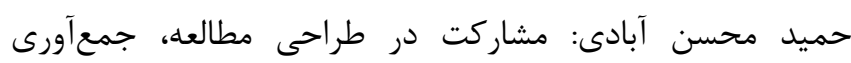

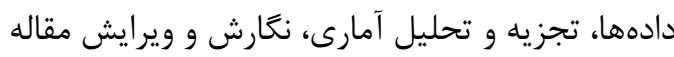

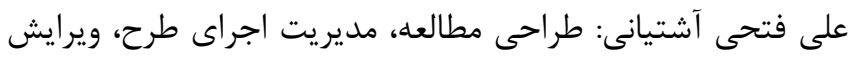
مقاله

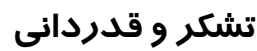

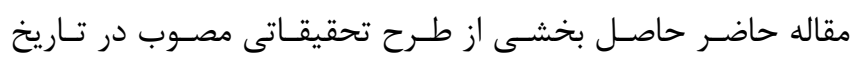

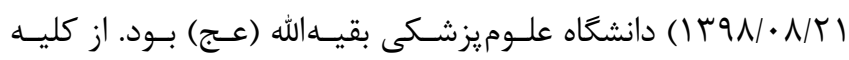

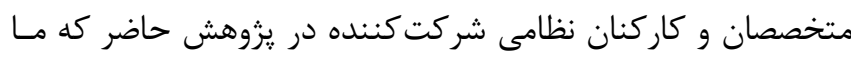
را در انجام اين مطالعه يارى نمودند كمال تشكر و قدردانى را داريم.

\section{منابع}

1. Kraaij V, De Wilde E. Negative life events and depressive symptoms in the elderly: a life span perspective. Aging \& Mental Health 2001;5:84-91

2. Sloan E, Hall K, Moulding R, Bryce S, Mildred H, Staiger PK. Emotion regulation as a transdiagnostic treatment construct across anxiety, depression, substance, eating and borderline personality disorders: A systematic review. Clinical Psychology Review 2017;57:141-163

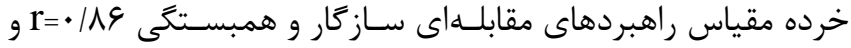

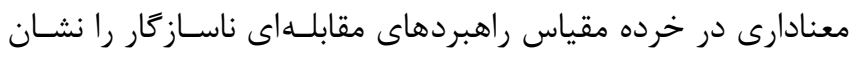

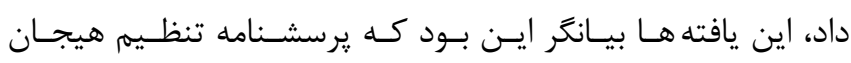

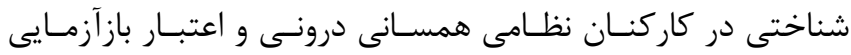

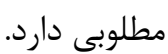
به طور كلى نتايج يزوهش حاضر نشان داد كه يزوهششكران مى توانند

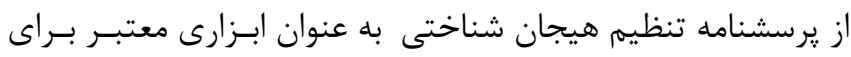

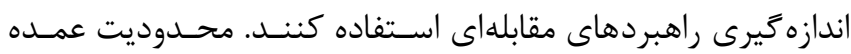

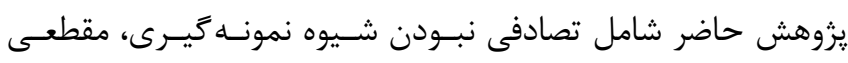

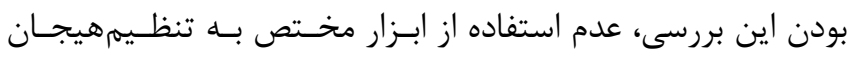

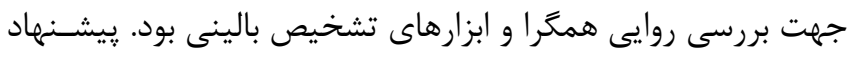

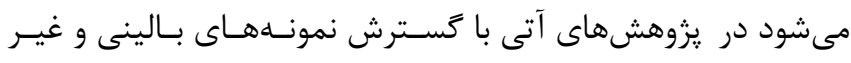

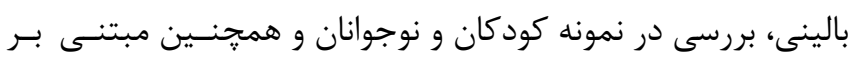

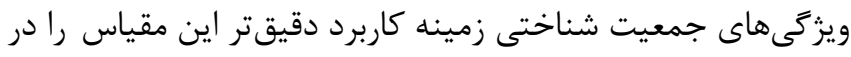
كَسترهاى بالينى و يزوهشى فراهم ساخت. بعلاوه، با توجه به اينكه

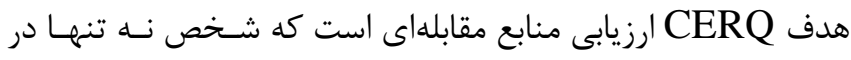

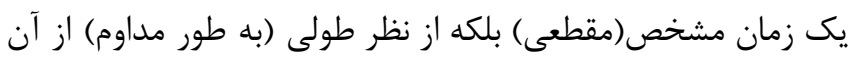

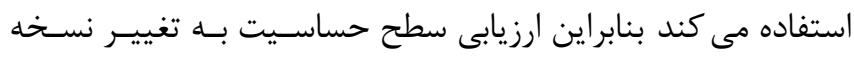

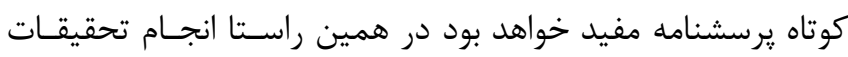

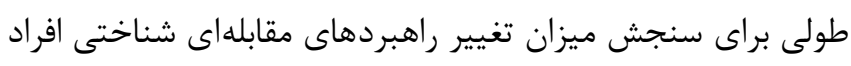

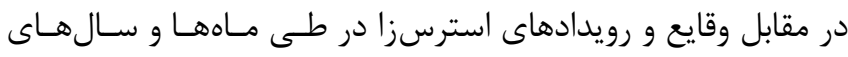

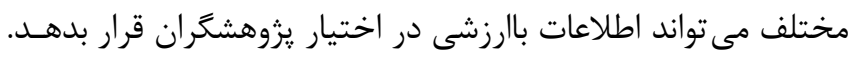

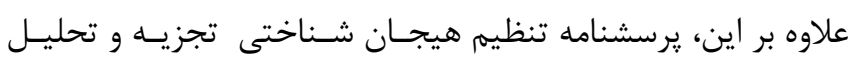

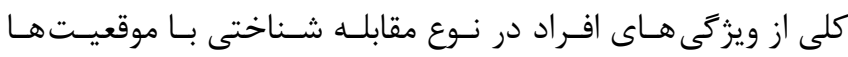

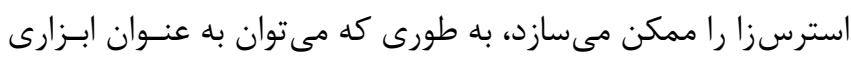

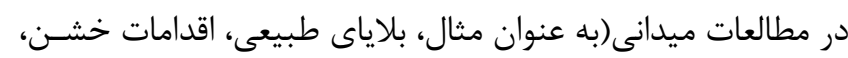

3. Kopp CB. Regulation of distress and negative emotions: A developmental view. Developmental Psychology 1989;25:343-354

4. Aldao A, Sheppes G, Gross JJ. Emotion regulation flexibility. Cognitive Therapy and Research 2015;39:263-278

5. Garnefski N, Kraaij V, Spinhoven P. Negative life events, cognitive emotion regulation and emotional problems. Personality and Individual Differences 2001;30:1311-1327 
6. John OP, Eng J. Three approaches to individual differences in affect regulation: Conceptualizations, measures, and findings. Handbook of emotion regulation, $2^{\text {th }}$ Edition, Guilford Press, New York, United States 2014

7. Gross JJ. The emerging field of emotion regulation: An integrative review. Review of General Psychology 1998;2:271-299

8. Garnefski N, Kraaij V. Cognitive emotion regulation questionnaire-development of a short 18item version (CERQ-short). Personality and Individual Differences 2006;41:1045-1053

9. Martin RC, Dahlen ER. Cognitive emotion regulation in the prediction of depression, anxiety, stress, and anger. Personality and Individual Differences 2005;39:1249-1260

10. Araujo APdC, Gadelha MJN, Melo RLPd. Evidence of validity, reliability and psychometric parameters of the items of the Cognitive Emotion Regulation Questionnaire-Short (CERQ-Short). PsicoUSF 2020;25:547-559

11. Garnefski N, Van Den Kommer T, Kraaij V, Teerds J, Legerstee J, Onstein E. The relationship between cognitive emotion regulation strategies and emotional problems: comparison between a clinical and a non-clinical sample. European Journal of Personality 2002;16:403-420

12. Garnefski N, Baan N, Kraaij V. Psychological distress and cognitive emotion regulation strategies among farmers who fell victim to the foot-and-mouth crisis. Personality and Individual Differences 2005;38:1317-1327

13. Garnefski N, Kraaij V. The cognitive emotion regulation questionnaire. European Journal of Psychological Assessment 2007;23:141-149

14. Berking M, Lukas CA. The Affect Regulation Training (ART): a transdiagnostic approach to the prevention and treatment of mental disorders. Current Opinion in Psychology 2015;3:64-69

15. Cakmak A, Cevik E. Cognitive emotion regulation questionnaire: Development of Turkish version of 18item short form. African Journal of Business Management 2010;4:2097-2102

16. Holgado-Tello FP, Amor PJ, Lasa-Aristu A, Domínguez-Sánchez FJ, Delgado B. Two new brief versions of the Cognitive Emotion Regulation Questionnaire and its relationships with depression and anxiety. Anales De Psicología/Annals of Psychology 2018;34:458-464
17. Ireland MJ, Clough BA, Day JJ. The cognitive emotion regulation questionnaire: Factorial, convergent, and criterion validity analyses of the full and short versions. Personality and Individual Differences 2017;110:90-95

18. Propheta I, van Zyl CJ. Measuring cognitive emotion regulation in South Africa using the Cognitive Emotion Regulation Questionnaire-short form. African Journal of Psychological Assessment 2019;1:1- 6

19. Besharat MA, Bazzazian S. Psychometric properties of the Cognitive Emotion Regulation Questionnaire in a sample of Iranian population. Advances in Nursing \& Midwifery 2015;24:61-70 [Persian]

20. DeVellis RF. Scale development: Theory and applications. $4^{\text {th }}$ Edition, Sage: United States, 2017

21. Lovibond PF, Lovibond SH. The structure of negative emotional states: Comparison of the Depression Anxiety Stress Scales (DASS) with the Beck Depression and Anxiety Inventories. Behaviour Research and Therapy 1995;33:335-343

22. Fathi Ashtiani, A. Psychological tests: Evaluation of Personality and Mental Health. $1^{\text {st }}$ Edition, Be'sat: Tehran, Iran, 2016 [Persian]

23. Macdonald S, Maclntyre $P$. The generic job satisfaction scale: Scale development and its correlates. Employee Assistance Quarterly 1997;13:116

24. Golparvar M, Taleb M. Mediating role of job satisfaction on the relationship between compulsory citizenship behaviors and organizational citizenship behaviors. Contemporary Psychology 2016;11:3346[Persian]

25. Hair JF, Black WC, Babin BJ, Anderson RE, Tatham R. Multivariate data analysis. $7^{\text {th }}$ Edition, Pearson Education, New Jersey, United States 2010

26. Potthoff S, Garnefski N, Miklósi M, Ubbiali A, Domínguez-Sánchez FJ, Martins EC, et al. Cognitive emotion regulation and psychopathology across cultures: A comparison between six European countries. Personality and Individual Differences 2016;98:218-224

27. Joormann J, Gotlib IH. Emotion regulation in depression: Relation to cognitive inhibition. Cognition and Emotion 2010;24:281-298

28. Gross JJ, John OP. Individual differences in two emotion regulation processes: implications for affect, relationships, and well-being. Journal of Personality and Social Psychology 2003;85:348 
29. Aldao A, Nolen-Hoeksema S, Schweizer S. Emotion-regulation strategies across psychopathology: A meta-analytic review. Clinical Psychology Review 2010;30:217-237

30. Aldao A. The future of emotion regulation research: Capturing context. Perspectives on Psychological Science 2013;8:155-172

31. Hofmann SG, Sawyer AT, Fang A, Asnaani A. Emotion dysregulation model of mood and anxiety disorders. Depression and Anxiety 2012;29:409-416 32. Vanderhasselt M-A, Koster EH, Onraedt T, Bruyneel L, Goubert L, De Raedt R. Adaptive cognitive emotion regulation moderates the relationship between dysfunctional attitudes and depressive symptoms during a stressful life period: A prospective study. Journal of Behavior Therapy and Experimental Psychiatry 2014;45:291-296

33. Zimmer-Gembeck MJ, Dunbar MD, Ferguson S, Rowe SL, Webb H, Skinner EA. Introduction to the special issue. Australian Journal of Psychology 2014;66:65-70

34. Cai W-p, Pan Y, Zhang S-m, Wei C, Dong W, Deng G-h. Relationship between cognitive emotion regulation, social support, resilience and acute stress responses in Chinese soldiers: Exploring multiple mediation model. Psychiatry Research 2017;256:71-78 35. Shahba S, Alvani S, Zahedi S, Memarzadeh G. An investigation on the effect of cognitive emotion regulation strategies on job satisfaction. Management Science Letters 2014;4:1315-1324 [Persian] 